\title{
Lasofoxifene as a potential treatment for therapy-resistant ER-positive metastatic breast cancer
}

\author{
Muriel Lainé', Sean W. Fanning², Ya-Fang Chang', Bradley Green', Marianne E. Greene', Barry Komm³,
} Justyna D. Kurleto', Linda Phung ${ }^{1}$ and Geoffrey L. Greene ${ }^{1 *}$ (D)

\begin{abstract}
Background: Endocrine therapy remains the mainstay of treatment for estrogen receptor-positive (ER+) breast cancer. Constitutively active mutations in the ligand binding domain of ERa render tumors resistant to endocrine agents. Breast cancers with the two most common ERa mutations, Y537S and D538G, have low sensitivity to fulvestrant inhibition, a typical second-line endocrine therapy. Lasofoxifene is a selective estrogen receptor modulator with benefits on bone health and breast cancer prevention potential. This study investigated the antitumor activity of lasofoxifene in breast cancer xenografts expressing Y537S and D538G ERa mutants. The combination of lasofoxifene with palbociclib, a CDK4/6 inhibitor, was also evaluated.
\end{abstract}

Methods: Luciferase-GFP tagged MCF7 cells bearing wild-type, Y537S, or D538G ERa were injected into the mammary ducts of NSG mice (MIND model), which were subsequently treated with lasofoxifene or fulvestrant as single agents or in combination with palbociclib. Tumor growth and metastasis were monitored with in vivo and ex vivo luminescence imaging, terminal tumor weight measurements, and histological analysis.

Results: As a monotherapy, lasofoxifene was more effective than fulvestrant at inhibiting primary tumor growth and reducing metastases. Adding palbociclib improved the effectiveness of both lasofoxifene and fulvestrant for tumor suppression and metastasis prevention at four distal sites (lung, liver, bone, and brain), with the combination of lasofoxifene/palbociclib being generally more potent than that of fulvestrant/palbociclib. X-ray crystallography of the ERa ligand binding domain (LBD) shows that lasofoxifene stabilizes an antagonist conformation of both wildtype and Y537S LBD. The ability of lasofoxifene to promote an antagonist conformation of Y537S, combined with its long half-life and bioavailability, likely contributes to the observed potent inhibition of primary tumor growth and metastasis of MCF7 Y537S cells.

Conclusions: We report for the first time the anti-tumor activity of lasofoxifene in mouse models of endocrine therapy-resistant breast cancer. The results demonstrate the potential of using lasofoxifene as an effective therapy for women with advanced or metastatic ER+ breast cancers expressing the most common constitutively active ERa mutations.

Keywords: Breast cancer, Endocrine resistant, Fulvestrant, Lasofoxifene, Selective estrogen receptor modulator

\footnotetext{
* Correspondence: ggreene@uchicago.edu

'The Ben May Department for Cancer Research, The University of Chicago,

929 East 57th Street, GCIS W421C, Chicago, IL 60637, USA

Full list of author information is available at the end of the article
}

(c) The Author(s). 2021 Open Access This article is licensed under a Creative Commons Attribution 4.0 International License, which permits use, sharing, adaptation, distribution and reproduction in any medium or format, as long as you give appropriate credit to the original author(s) and the source, provide a link to the Creative Commons licence, and indicate if changes were made. The images or other third party material in this article are included in the article's Creative Commons licence, unless indicated otherwise in a credit line to the material. If material is not included in the article's Creative Commons licence and your intended use is not permitted by statutory regulation or exceeds the permitted use, you will need to obtain permission directly from the copyright holder. To view a copy of this licence, visit http://creativecommons.org/licenses/by/4.0/ The Creative Commons Public Domain Dedication waiver (http://creativecommons.org/publicdomain/zero/1.0/) applies to the data made available in this article, unless otherwise stated in a credit line to the data. 


\section{Introduction}

Breast cancer is the most common cause of cancer mortality in women worldwide [1]. Approximately $80 \%$ of breast cancers are estrogen receptor positive $(E R+)$ [2]. Evidence suggests that estrogen receptor alpha (ER $\alpha$, encoded by ESR1), a member of the nuclear receptor family of transcription factors, is involved in the initiation and progression of ER+ breast tumors [3]. Estradiol (E2) binding to the ER causes receptor dimerization to its active form for coactivator binding, leading to enhanced proliferation and survival of breast epithelial cells through the transcriptional modulation of genes $[3,4]$.

Endocrine therapy that inhibits ER $\alpha$ activity remains the mainstay of treatment for ER+ breast cancer. Tamoxifen, a selective estrogen receptor modulator (SERM), acts as a partial antagonist for ER $\alpha$, and aromatase inhibitors (AIs) inhibit estrogen production [3]. However, a number of patients either are de novo resistant to these therapies [5] or become resistant after prolonged exposure to these drugs [6], and experience cancer recurrence in the 5 to 20 years following treatment completion [7]. Fulvestrant (FUL), the only approved selective estrogen receptor down regulator (SERD), has been shown to be effective in treating endocrine therapy-resistant tumors [8], but the challenges of drug resistance remain even for FUL [9].

Several mechanisms have been suggested for endocrine-therapy resistance $[4,6]$. One important mechanism involves acquired ESR1 mutations under the selective pressure of endocrine therapy treatments, especially aromatase inhibitors. The ESR 1 mutations are detected almost exclusively in the ligand binding domain (LBD), which includes the major transcriptional activating function-2 (AF2) [3]. In patients with metastatic ER+ breast cancer, these mutations have been observed at a frequency of $10-40 \%$, but are rarely detected in primary tumors [10-12]. The two most common ESR1 mutations are Y537S and D538G, located at the N-terminus of helix 12 (H12), a key structural regulator of coactivator recruitment in the LBD of ER $\alpha$ [10-13]. The conformational changes in $\mathrm{H} 12$ caused by these mutations give rise to a constitutively active receptor that can interact with coactivators, independent of ligand, and has reduced affinity for agonists and antagonists, thereby conferring reduced sensitivity of the mutants to endocrine drugs such as tamoxifen or FUL [10-14]. Additionally, allele-specific neomorphic properties found in these mutants could also contribute to cancer metastasis [15]. These limitations prompted the search for new treatment strategies that would be effective against breast cancers expressing known ER $\alpha$ mutants, including a SERM that might also alleviate postmenopausal symptoms related to estrogen loss, while inhibiting breast cancer progression. Raloxifene is the only SERM other than tamoxifen currently approved for reducing invasive breast cancer risk in postmenopausal women [16]. Bazedoxifene, a third-generation SERM, has shown potential anti-tumor effects in animal models with therapyresistant breast cancer $[17,18]$.

Lasofoxifene (LAS), also a third-generation SERM, was developed to treat postmenopausal vaginal atrophy and osteoporosis [19] and approved but not used in Europe for osteoporosis treatment in postmenopausal women at increased risk of fracture [20]. In the Postmenopausal Evaluation and Risk-Reduction with Lasofoxifene (PEAR L) trial, 5 years of LAS was associated with reduced risk of $79 \%$ for total breast cancers and $83 \%$ for invasive ER+ breast cancer and had beneficial effects on vertebral and non-vertebral fractures, coronary heart disease events, and stroke [21]. A network meta-analysis of randomized controlled trials on breast cancer chemoprevention agents showed that similar to raloxifene, LAS elicited a better benefit-risk profile than tamoxifen and AIs [22]. However, LAS has not been tested as a therapeutic option for progressive breast cancer. A recent cell-based study showed that the antagonist activity of LAS on ER+ breast cancer cells was not affected by the expression level of activating $\mathrm{ER} \alpha$ mutants relative to wild-type (WT) ER $\alpha$, a property not observed for other agents tested, including tamoxifen, bazedoxifene, raloxifene, and FUL [23].

The objective of these studies was to investigate the potential benefit of LAS on endocrine-resistant ER+ metastatic breast cancer (MBC) in human-derived xenograft models harboring Y537S and D538G ESR1 mutations, the most commonly observed ER $\alpha$ mutations. In addition, effectiveness on tumor inhibition by LAS combined with palbociclib (PAL), a CDK4/6 inhibitor that blocks cell-cycle progression and has been shown to enhance the efficacy of endocrine agents [24, 25], was evaluated. Notably, LAS alone or in combination with PAL was an effective inhibitor of tumor growth in the MCF7 Y537S ER $\alpha+$ MBC xenograft model. Additionally, the LAS/PAL combinations were notably more effective than the FUL/PAL combinations at inhibiting tumor growth and metastasis to the lung, liver, brain, and long bones. Structural analyses showed that LAS stabilizes an antagonist conformation of both WT and Y537S ER $\alpha$ LBDs.

\section{Materials and methods \\ Cell lines}

MCF7 breast cancer cells bearing WT and mutant (Y537S and D538G) ER $\alpha$ were kindly provided by Dr. Ben Park of the Sidney Kimmel Cancer Center at Johns Hopkins University [26]. The mutant cell lines were heterozygous, with both WT and mutant ER $\alpha$ expressed. MCF7 cells were transduced with a lentivirus vector 
(pFU-Luc2-eGFP) encoding a luciferase and green fluorescent protein (GFP) fusion gene driven by a ubiquitin promoter at a $\mathrm{MOI}=5$ in suspension and then plated [27]. Cells were cultured in DMEM containing 5\% FBS and genotyped prior to injection in mice. DNA was extracted with DNeasy Blood and Tissue Kit (Qiagen Cat\#69504) and the presence of the ER $\alpha$ mutations was verified by sequencing with CCCCTTCTAGGGATTT $\mathrm{CAGC}$ as the sequencing primer.

\section{Breast cancer models}

Mouse studies were performed in compliance with an approved Institutional Animal Care and Use Committee protocol at the University of Chicago. To better mimic the progression of ductal lesions to invasive disease, a mammary intraductal (MIND) mouse model [28, 29] was used. NSG (NOD.Cg-Prkdc ${ }^{\text {scid }} \mathrm{Il} 2 \mathrm{rg}^{\mathrm{tm} 1 \mathrm{Wjl}} / \mathrm{SzJ}$ ) mice (Jackson Laboratories) were anesthetized by intraperitoneal injections with a ketamine/xylazine $(100 / 5 \mathrm{mg} / \mathrm{kg})$ mixture in PBS prior to cancer cell injections. Single-cell suspensions of 250,000 WT or mutant MCF7 cells were injected in the mammary ducts of inguinal glands as previously described $[28,29]$. Tumor cell growth in situ was followed once weekly or biweekly after injection via luminescence imaging with a Xenogen IVIS 200 instrument in the Integrated Small Animal Imaging Research Resource at the University of Chicago. Mice were injected with $100 \mu \mathrm{L}$ of $0.1 \mathrm{M}$ luciferin in PBS (Perkin Elmer XenoLight Cat\#122799) prior to imaging. Effects were evaluated in the models expressing WT, Y537S, and D538G ER $\alpha$ for monotherapies, and in the model expressing Y537S ER $\alpha$ for combination therapies.

\section{Treatment}

Treatment was initiated 2 to 3 weeks (dose-response study) or at day 20 (combination study) after cancer cell injections. For the dose-response study, LAS at 1, 5, or $10 \mathrm{mg} / \mathrm{kg}$ in $100 \mu \mathrm{L}$ of PBS containing 15\% PEG 400, or vehicle, was administered 5 days/week via subcutaneous (s.c.) injection, while FUL $5 \mathrm{mg} /$ mouse (Med Chem Express Cat\#HY-13636) in $100 \mu \mathrm{l}$ of mineral oil was injected s.c. once per week. For the combination study, PAL (Med Chem Express Cat\#HY-50567) at 35 or 70 $\mathrm{mg} / \mathrm{kg}$ in $100 \mu \mathrm{L}$ of $50 \mathrm{mM}$ sodium lactate $(\mathrm{pH} 4)$ was administered via oral gavage 5 days/week either alone or in combination with LAS or FUL. Mice were sacrificed 70 days after treatment initiation (dose-response study) or 82 days after cancer cell injection (combination study), and mammary gland tumors were weighed. Metastases were evaluated with ex vivo imaging of excised long bones, brains, lungs, and livers and quantified by luciferase activity for the combination study.

\section{Histological analysis}

Tissues were harvested and fixed in formalin. Hematoxylin and eosin (H\&E) staining was performed for livers and long bones. Immunohistochemical (IHC) staining was performed for lungs with human cytokeratin AE1/AE3 (dose-response study) or anti-luciferase antibody (combination study), and for long bones with anti-luciferase antibody. Histological analysis was performed by the Human Tissue Resource Center (HRTC) at the University of Chicago. Primary antibody for human cytokeratin AE1/AE3 (Biocare Medical Cat\#CM011A) or antiluciferase antibody (abcam $\# 181640$ ) was used at $1 / 2000$ dilution to visualize tumor cells. IHC and H\&E stained sections were scanned on a CRi Pannoramic Scan whole slide scanner. A Nikon Eclipse Ti2 microscope with a $\times 10$ objective was used to obtain high-resolution images. Percent area of liver metastasis (the area of tumor cells normalized to the total liver area) was analyzed using the ImageJ-FIJI software. Lung and bone metastases were analyzed using the NSIElements software from Nikon. Results were plotted as histogram +/- SEM or using a boxplot.

\section{Crystallography}

The WT and Y537S ER $\alpha$ LBDs with all solventexposed cysteines mutated to serines were expressed in Escherichia coli BL21(DE3) and purified using NiNTA resin and size exclusion chromatography, as previously described [30]. Peak fractions corresponding to dimeric LBD were pooled and concentrated to $10 \mathrm{mg} / \mathrm{mL}$. The products were then flash frozen and kept at $-80^{\circ} \mathrm{C}$. For crystallization, proteins were thawed on ice and LAS was added at $1 \mathrm{mM}$ for up to $3 \mathrm{~h}$ on ice. Hanging drop vapor diffusion was used to grow protein crystals. Each complex was crystallized in either PEG 3350 or PEG 8000 at pH 6-8 with 200 $\mathrm{mM} \mathrm{MgCl}_{2}$. X-ray data sets were collected on the SBC 19-BM beamline at the Advanced Photon Source Argonnne National Laboratory. Data were scaled, merged, and integrated using HKL-3000. Structures were solved at $1.8 \AA$ for WT ER $\alpha$ LBD complex and $2.1 \AA$ for Y537S ER $\alpha$ LBD complex using molecular replacement and manual coordinate editing, and refined using Phenix and Coot. All coordinates and structure factors were deposited in the Protein Data Bank (PDB) with accession codes 6VJD for the WT LBD/LAS complex and 6VGH for the Y537S LBD/ LAS complex. Supplementary Table S1 shows $\mathrm{x}$-ray crystallographic data collection and refinement statistics. Supplementary Figure S1 shows 2mFo-DFc difference maps for representative LAS ligands in the ER $\alpha$ LBD binding pocket for the WT and Y537S structures. 


\section{ER binding assays}

The purified ER $\alpha$ LBDs of $5 \mathrm{nM}$ were incubated with 10 $\mathrm{nM}\left[{ }^{3} \mathrm{H}\right]$-E2 with varying concentrations $(0.1 \mathrm{nM}$ to 10 $\mu \mathrm{M})$ of competitors (LAS and 4-hydroxytamoxifen [4OHT]) in binding buffer (10 mM Tris $\mathrm{pH}$ 7.6, $300 \mathrm{mM}$ $\mathrm{NaCl}, 5 \mathrm{mM}$ EDTA, $10 \%$ glycerol, $1 \mathrm{mM}$ DTT). After a 1-h incubation on ice, $50 \mu \mathrm{L}$ of each reaction was loaded onto a CPG column at $4{ }^{\circ} \mathrm{C}$ in triplicate and incubated for $5 \mathrm{~min}$. The columns were then washed with approximately $10 \mathrm{~mL}$ wash buffer (10 mM Tris pH 7.4, $400 \mathrm{mM}$ $\mathrm{NaCl})$ to remove unbound ligands. Remaining $\left[{ }^{3} \mathrm{H}\right]-\mathrm{E} 2$ was eluted with $1 \mathrm{~mL}$ ethanol and counted in a liquid scintillation counter. Data were analyzed as described previously [13, 31].

\section{Statistical analysis}

GraphPad Prism 7 software was used to analyze data and create graphs and boxplots. P-values were determined using unpaired, two-tailed $t$-test, Fisher's exact test, or one-way ANOVA, with $p \leq 0.05$ considered statistically significant.

\section{Results}

\section{Tumor growth with LAS monotherapy}

Tumors derived from mutant Y537S and D538G cells grew faster than tumors from WT MCF7 cells. In vivo real-time luminescence imaging showed that LAS alone ( 5 and $10 \mathrm{mg} / \mathrm{kg}$ ) reduced tumor mass compared with vehicle control in xenograft tumors expressing WT, Y537S, and D538G ER $\alpha$, similar to FUL (Fig. 1a and Supplementary Figure S2). For the two mutants, the total photon flux quantification of luminescence signal over time demonstrated that LAS was more effective than FUL at inhibiting tumor growth, with the highest dose of LAS $(10 \mathrm{mg} / \mathrm{kg})$ eliciting a superior inhibitory effect versus FUL (Fig. 1b). Based on observed radiance alone, potential tumor shrinkage with vehicle control towards day 56 after treatment initiation was observed for Y537S and D538G tumors (Fig. 1b), which was likely an artifact as this phenomenon was not observed in later experiments.

Data on final primary tumor weight at sacrifice correlated with the in vivo luminescence imaging results, with a more obvious and statistically robust dose effect for LAS, especially for the Y537S mutant. Significantly lower terminal tumor weights were observed for FUL and LAS relative to vehicle in the three mouse models (Fig. 1c). Reduction in tumor weight with 5 and $10 \mathrm{mg} / \mathrm{kg}$ of LAS was approximately 60\% for Y537S and 50\% for D538G. Final tumor weights were much lower in mice injected with MCF7 cells expressing WT ER $\alpha$ compared with the other two MCF7 variants, reflecting the slower growth of WT versus mutant tumors, as expected. LAS 5 or 10 $\mathrm{mg} / \mathrm{kg}$ resulted in significantly lower tumor weights for both ER $\alpha$ mutants versus FUL. However, FUL appeared to be more effective than LAS at inhibiting WT tumor.

\section{Metastasis with LAS monotherapy}

Histological analysis revealed metastases of the primary tumor to the lung and the liver in vehicle-treated mice, with the total area of lung metastases considerably larger for Y537S and D538G than for WT (Fig. 2). LAS at 10 $\mathrm{mg} / \mathrm{kg}$ decreased lung metastases in all three mouse models as shown by IHC staining (Fig. 2a). In WT tumors, LAS at all tested doses reduced lung metastases to a level comparable to that by FUL (average percent area of metastasis: $4 \%$ by vehicle, $0.9-1.5 \%$ by LAS, and $1 \%$ by FUL, $p=\mathrm{NS}$; Fig. 2b). For both mutant tumors, the inhibitory effect of LAS appeared dose dependent, with the two higher doses almost completely blocking metastasis, although a significant difference versus vehicle was only observed for $5 \mathrm{mg} / \mathrm{kg}$ LAS in D538G mice. FUL versus vehicle completely blocked lung metastasis of WT tumors and significantly blocked lung metastasis of D538G but not Y537S tumors.

Similarly, H\&E staining showed that LAS inhibited metastasis to the liver for both mutants, while FUL only had an effect on D538G (Fig. 2c). Quantification of metastatic coverage confirmed that LAS at 5 and $10 \mathrm{mg} /$ $\mathrm{kg}$ was significantly more effective at reducing liver metastases of Y537S mutant cells compared with vehicle and FUL (Fig. 2d). The D538G tumors were less metastatic (with smaller metastases) than the Y537S tumors in the liver, and no liver metastases were observed in D538G mice treated with LAS or FUL (Fig. 2d).

\section{Effect of combination therapies on tumor growth}

In vivo real-time luminescence data of Y537S mice showed that LAS alone at 5 or $10 \mathrm{mg} / \mathrm{kg}$ slowed tumor growth relative to vehicle, with a clear efficacy advantage over FUL (Fig. 3a). Inhibition was observed as early as 10 to 20 days after the treatment initiation with LAS or LAS/PAL combinations, unlike FUL alone, which did not have any effect at early time points. PAL alone at 35 $\mathrm{mg} / \mathrm{kg}$ also suppressed primary tumor growth with a slightly slower increase over time than FUL, while the effect of $70 \mathrm{mg} / \mathrm{kg}$ PAL alone was similar to that of 10 $\mathrm{mg} / \mathrm{kg}$ LAS. The combination of PAL with LAS or FUL enhanced the inhibitory activity of each drug alone, except for $5 / 35 \mathrm{mg} / \mathrm{kg}$ LAS/PAL versus LAS alone and 5 $\mathrm{mg} /$ mouse FUL/70 mg/kg PAL versus PAL alone. However, the LAS/PAL combinations were notably more effective than the FUL/PAL combinations based on the luminescence data.

Terminal tumor weights reflected the real-time luminescence imaging well. All treatments tested, including LAS, FUL, and PAL alone, and the combinations of PAL with LAS or FUL, significantly reduced primary tumor 


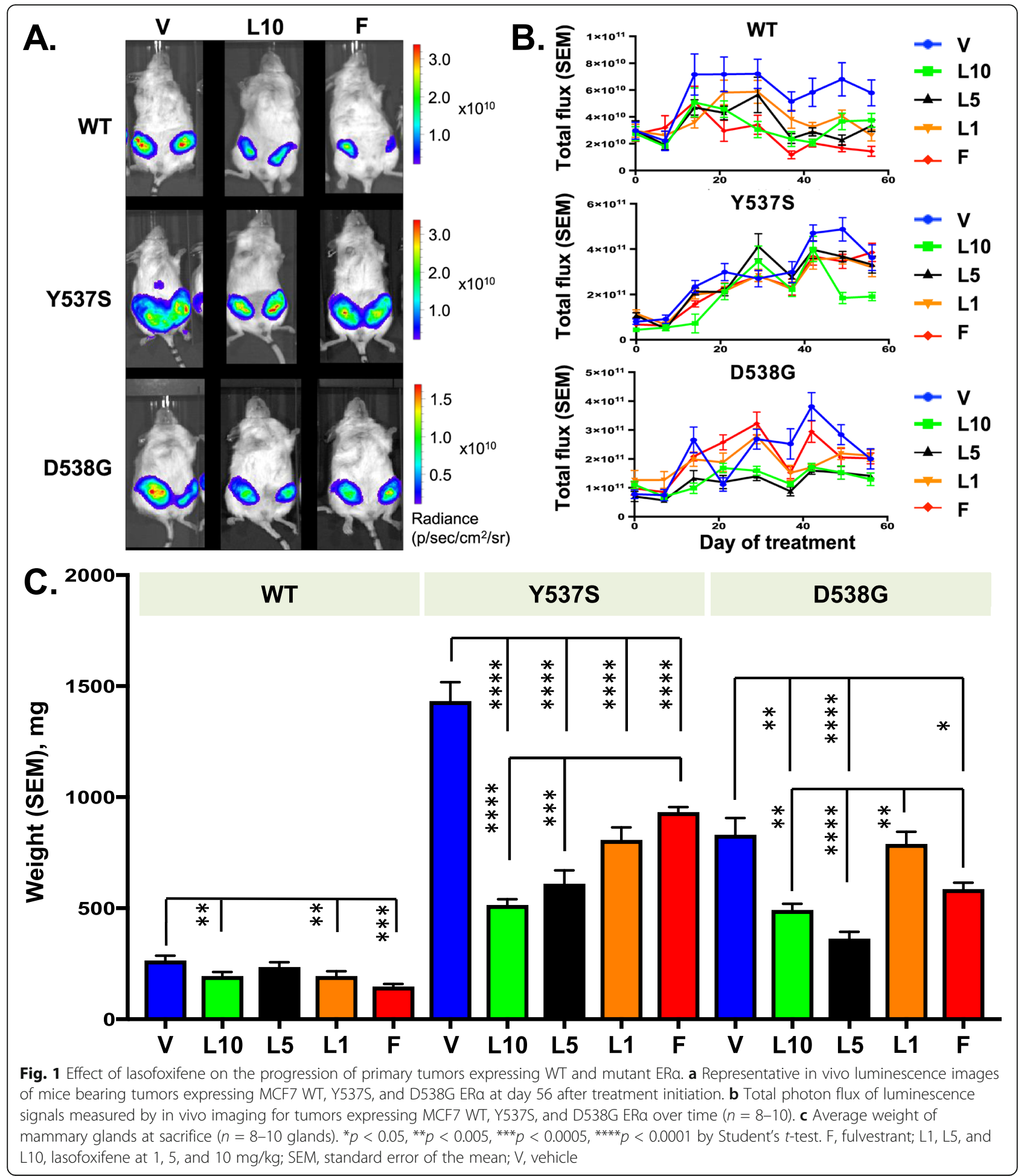

mass relative to vehicle control (Fig. $3 \mathrm{~b}$ ). Both doses of LAS alone significantly decreased tumor weights compared with FUL and PAL monotherapies (except for 10 $\mathrm{mg} / \mathrm{kg}$ LAS vs $70 \mathrm{mg} / \mathrm{kg}$ PAL, $p=\mathrm{NS}$ ). Interestingly, LAS reduced tumor weight more at $5 \mathrm{mg} / \mathrm{kg}$ than 10 $\mathrm{mg} / \mathrm{kg}$. While the effect of PAL was stronger at the higher dose tested, both doses of PAL were significantly more effective than FUL alone. Addition of PAL at either dose significantly improved the effectiveness of FUL, although the activity of FUL/PAL was not significantly different from that of PAL alone at corresponding doses. Moreover, the combinations of $5 / 70 \mathrm{mg} / \mathrm{kg}$ and 

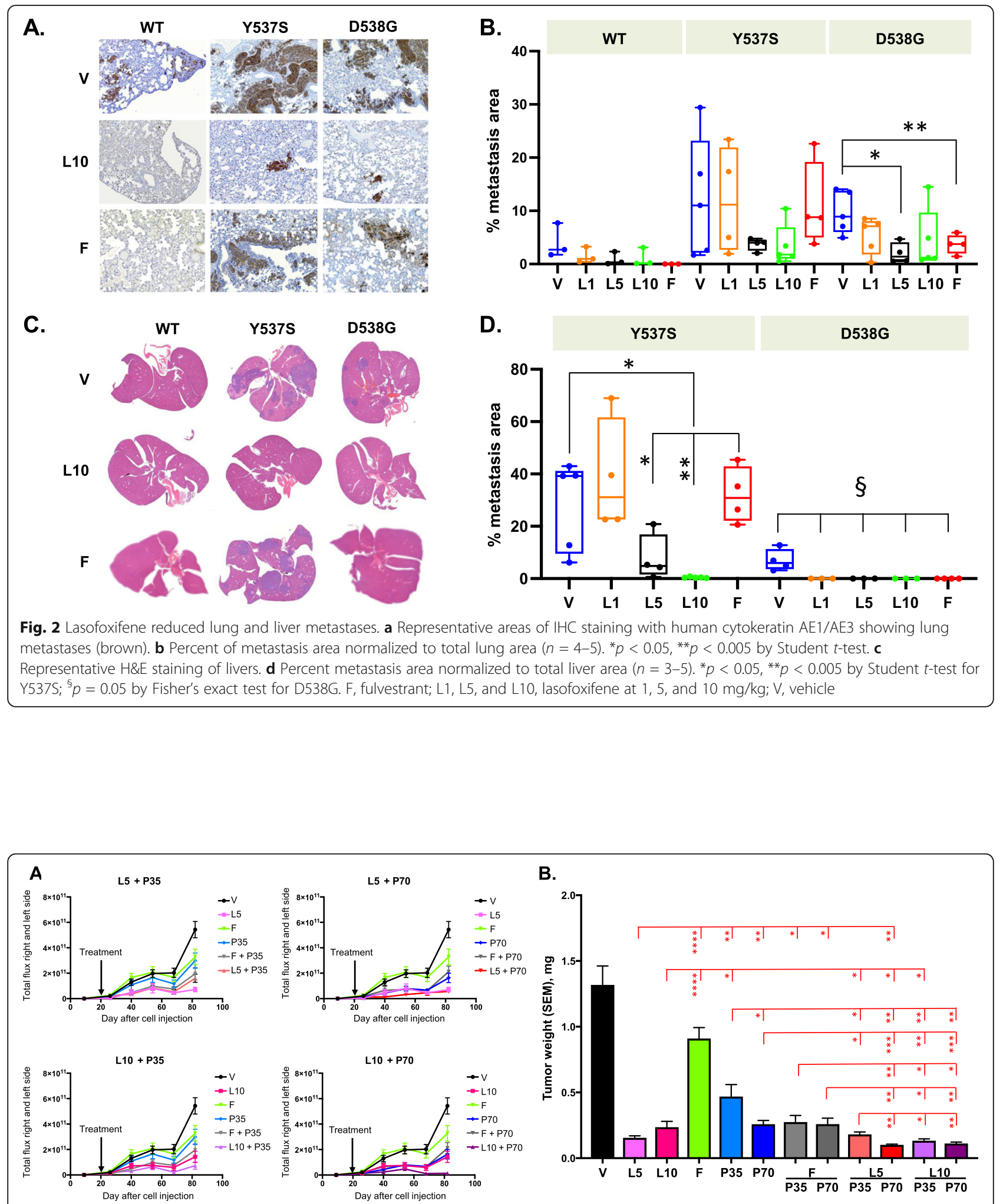

Fig. 3 Effect of combination therapies on primary tumor growth in the Y537S ERa mutant model. a Total photon flux of luminescence signals measured by in vivo imaging over time for different dose combinations of lasofoxifene and palbociclib. b Tumor weight at sacrifice $(n=5-6)$. ${ }^{*} p$ $<0.05,{ }^{* *} p<0.01,{ }^{* * *} p<0.001,{ }^{* * *} p<0.0001$ by one-way ANOVA. Additional $p$-values not shown: $p<0.05$ for vehicle vs fulvestrant; $p<0.0001$ for vehicle vs every other treatment; $p<0.01$ for fulvestrant vs palbociclib $35 \mathrm{mg} / \mathrm{kg} ; p<0.0001$ for fulvestrant vs every other treatment. $\mathrm{F}$, fulvestrant; L5 and L10, lasofoxifene at 5 and $10 \mathrm{mg} / \mathrm{kg}$; P35 and P70, palbociclib at 35 and $70 \mathrm{mg} / \mathrm{kg}$; SEM, standard error of the mean; V, vehicle 
10/35 mg/kg LAS/PAL were significantly more effective than either drug alone. Compared with FUL/PAL, the LAS/PAL combinations led to significantly lower final tumor weight, except for $5 / 35 \mathrm{mg} / \mathrm{kg}$ LAS/PAL $(p=$ NS).

\section{Effect of combination therapies on tumor metastasis}

Quantification of ex vivo radiance of excised long bones, brains, lungs, and livers from treated mice showed that monotherapies with both doses of LAS and PAL reduced metastases of Y537S mutant tumor cells to the four distal sites compared with vehicle only, while FUL alone did not show any effect (Fig. 4). Reduced metastases were generally observed with LAS versus PAL, and, similar to the effect on primary tumors (Fig. 3), with the lower versus higher dose of LAS at all four sites. The inhibitory effect of $5 \mathrm{mg} / \mathrm{kg}$ LAS was only enhanced by 70 $\mathrm{mg} / \mathrm{kg}$ PAL at the lung (Fig. 4c). Improvements versus single agents on metastasis inhibition at the four sites were observed when $10 \mathrm{mg} / \mathrm{kg}$ LAS was combined with
PAL, except for $10 / 35 \mathrm{mg} / \mathrm{kg} \mathrm{LAS} / \mathrm{PAL}$ at the brain (Fig. 4b) and 10/70 mg/kg LAS/PAL at the liver (Fig. 4d). While addition of PAL at either dose significantly improved the effectiveness of FUL, $70 \mathrm{mg} / \mathrm{kg}$ PAL alone was more beneficial than its combinations with FUL at the bone, lung, and liver (Fig. 4a, c, d). Notably, LAS/ PAL combinations were in general more effective than FUL/PAL combinations at inhibiting metastasis of Y537S cells to all distal sites tested (Fig. 4a, c, d) except for the brain, for which only the $10 / 70 \mathrm{mg} / \mathrm{kg}$ LAS/PAL combination elicited a stronger inhibitory effect versus FUL/PAL (Fig. 4b).

Data from histological assessments of metastatic burden in the lung, liver, and bone were consistent with the ex vivo imaging results. LAS was substantially more effective than FUL in preventing metastasis to the lung and liver, regardless of the presence of PAL (Fig. 5). Compared with single agents alone, FUL plus $35 \mathrm{mg} / \mathrm{kg}$ PAL reduced metastatic coverage in both the liver and the lung (Fig. 5b, d), 10/70 mg/kg LAS/PAL did in the
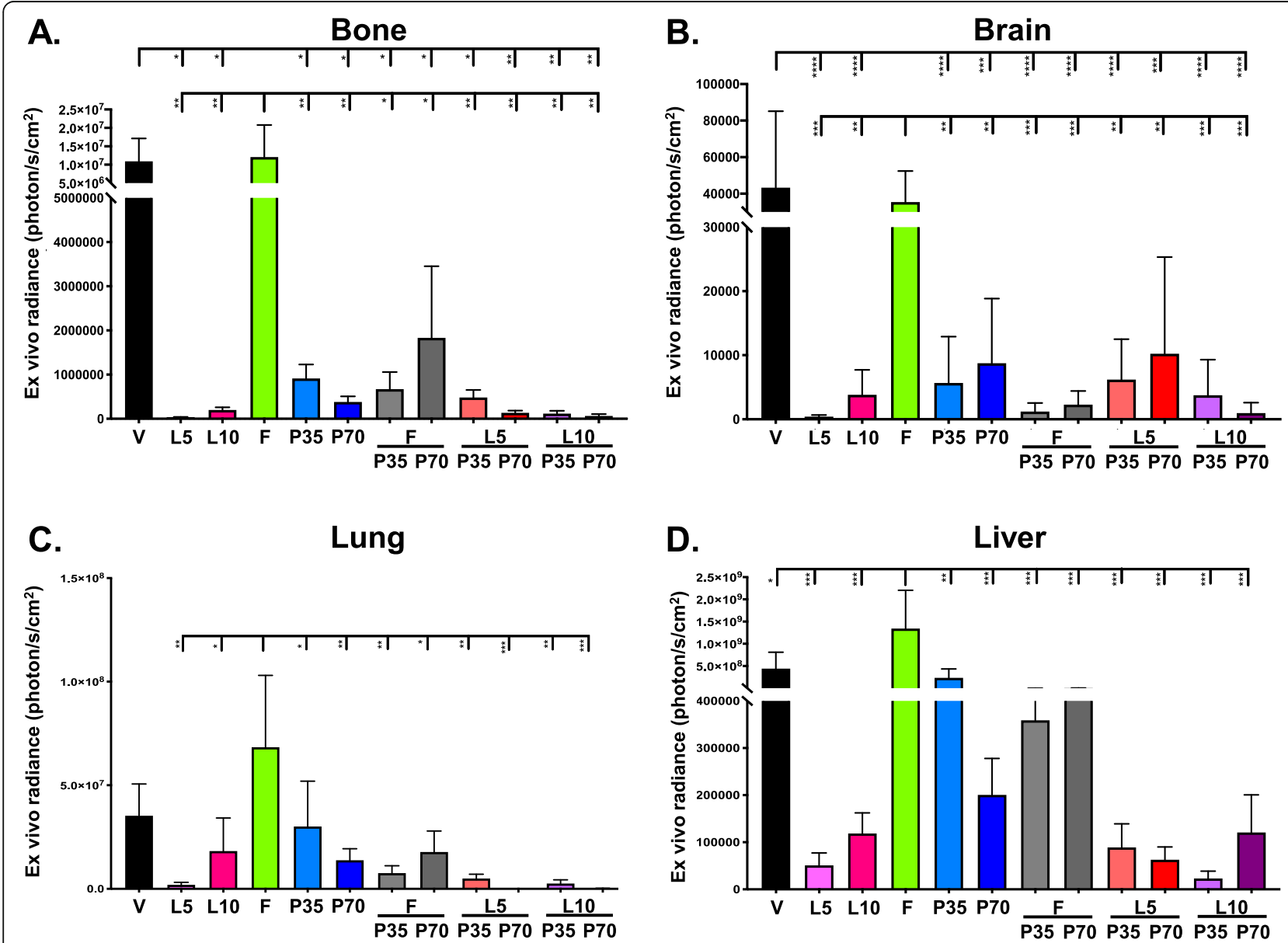

Fig. 4 Effect of combination therapies on tumor metastasis in the Y537S ERa mutant model. Ex vivo radiance of luciferase activity was measured in excised a long bones ( $n=10-12$ legs), $\mathbf{b}$ brains ( $n=5-6$ mice), $\mathbf{c}$ lungs ( $n=5-6$ mice), and $\mathbf{d}$ livers $(n=5-6$ mice). Error bars represent standard error of the mean. F, fulvestrant; L5 and L10, lasofoxifene at 5 and $10 \mathrm{mg} / \mathrm{kg} ; \mathrm{P} 35$ and P70, palbociclib at 35 and $70 \mathrm{mg} / \mathrm{kg} ; \mathrm{V}$, vehicle. ${ }^{*} p$ $<0.05,{ }^{* *} p<0.01,{ }^{* * *} p<0.001,{ }^{* * *} p<0.0001$ by one-way ANOVA 

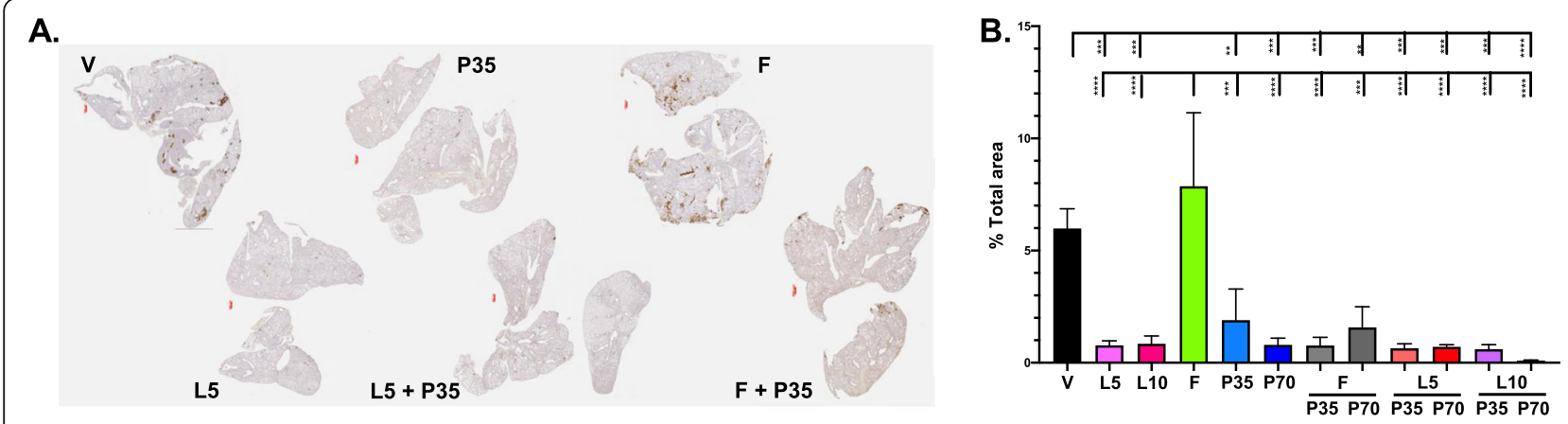

C.

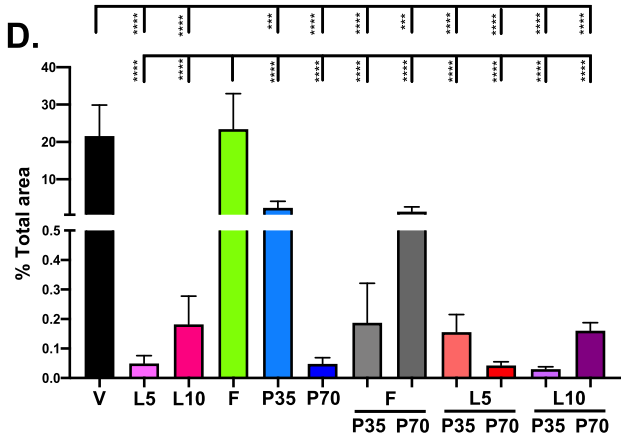

Fig. 5 Histological analysis of lungs and livers in the Y537S ERa mutant model. a Representative IHC staining of lungs with anti-luciferase antibody showing lung metastases (brown). b Quantitation of the IHC staining showing metastasis as percent of total lung area ( $n=5-6$ mice). $\mathbf{c}$ Representative H\&E staining of livers. d Quantitation of the H\&E staining showing the area of tumor cells normalized to the total liver area $(n=$ 5-6 mice). Error bars represent standard error of the mean. F, fulvestrant; L5 and L10, lasofoxifene at 5 and 10 mg/kg; P35 and P70, palbociclib at 35 and $70 \mathrm{mg} / \mathrm{kg}$; $\mathrm{V}$, vehicle. ${ }^{*} p<0.05,{ }^{* *} p<0.01,{ }^{* *} p<0.001,{ }^{* * *} p<0.0001$ by one-way ANOVA

lung (Fig. 5b), and 10/35 $\mathrm{mg} / \mathrm{kg}$ LAS/PAL did in the liver (Fig. 5d). H\&E and IHC staining of bone marrow showed that $5 \mathrm{mg} / \mathrm{kg}$ LAS completely blocked tumor metastases to the bone, in contrast to vehicle control (Supplementary Figure S3). Both bone metastases and necrosis were observed in vehicle- and FUL-treated mice, but not in other treatment groups (Supplementary Table S2).

\section{Binding affinity for ERa LBD}

Binding affinity of LAS for WT ER $\alpha$ LBD $\left(K_{\mathrm{i}}=0.21 \pm\right.$ $0.06 \mathrm{nM})$ was comparable to that of E2 $\left(K_{\mathrm{d}}=0.22 \pm 0.11\right.$ $\mathrm{nM})$, but lower compared to $4-\mathrm{OHT}\left(K_{\mathrm{i}}=0.12 \pm 0.003\right.$ $\mathrm{nM})$ and FUL $\left(K_{\mathrm{i}}=0.13 \pm 0.03 \mathrm{nM}\right)$ (Table 1). ESR1

Table 1 Ligand-binding affinities for WT and mutant ERa LBDs

\begin{tabular}{|c|c|c|c|}
\hline \multirow[b]{2}{*}{ Ligand } & \multicolumn{3}{|c|}{$\mathrm{K}_{\mathrm{i}} \pm \mathrm{SD}, \mathrm{nM}$ (fold change over WT) } \\
\hline & WT & Y537S & D538G \\
\hline 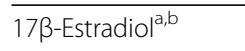 & $0.22 \pm 0.11$ & $1.40 \pm 0.54(6.36)$ & $1.77 \pm 0.66(8.05)$ \\
\hline Lasofoxifene & $0.21 \pm 0.06$ & $2.34 \pm 0.60(11.14)$ & $2.19 \pm 0.24(10.43)$ \\
\hline 4-Hydroxytamoxifen & $0.12 \pm 0.003$ & $2.64 \pm 0.40(22.00)$ & $2.29 \pm 0.80(19.08)$ \\
\hline Fulvestrant $^{\mathrm{b}}$ & $0.13 \pm 0.03$ & $3.68 \pm 0.77(28.31)$ & $5.06 \pm 1.16(38.92)$ \\
\hline
\end{tabular}

$\angle B D$, ligand binding domain; $S D$, standard deviation; $W T$, wild type

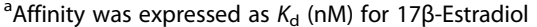

bPreviously published data from Zhao et al. [14] mutations reduced the affinities of LAS, 4-OHT, and FUL by approximately 10 to 40 folds relative to that for WT. The $K_{\mathrm{i}}$ of LAS, 4-OHT, and FUL was $2.34 \pm$ $0.60 \mathrm{nM}, 2.64 \pm 0.40 \mathrm{nM}$, and $3.68 \pm 0.77 \mathrm{nM}$, respectively, for Y537S binding, and $2.19 \pm 0.24 \mathrm{nM}$, $2.29 \pm 0.80 \mathrm{nM}$, and $5.06 \pm 1.16 \mathrm{nM}$, respectively, for D538G binding (Table 1).

\section{Antagonist conformation of ERa LBD}

$\mathrm{X}$-ray crystallography showed that LAS stabilized an antagonist conformation of both WT and Y537S ER $\alpha$ LBD, although the loop connecting $\mathrm{H} 11$ to $\mathrm{H} 12$ was absent in the Y537S structure (Fig. 6). Superposition of the crystal structures at alpha carbons shows that $\mathrm{H} 12$ is less helical and sits slightly away from AF2-cleft in the Y537S compared with to the WT. In the Y537S structure, LAS itself adopts a vector that places its pyrrolidine moiety closer to H12, likely to take the space that was occupied by the H11/12 loop in the WT structure. Only A chains were inspected as B chains show significant crystal contacts near $\mathrm{H} 12$.

\section{Discussion}

We report for the first time the anti-tumor activity of LAS in mouse models of endocrine-resistant breast 


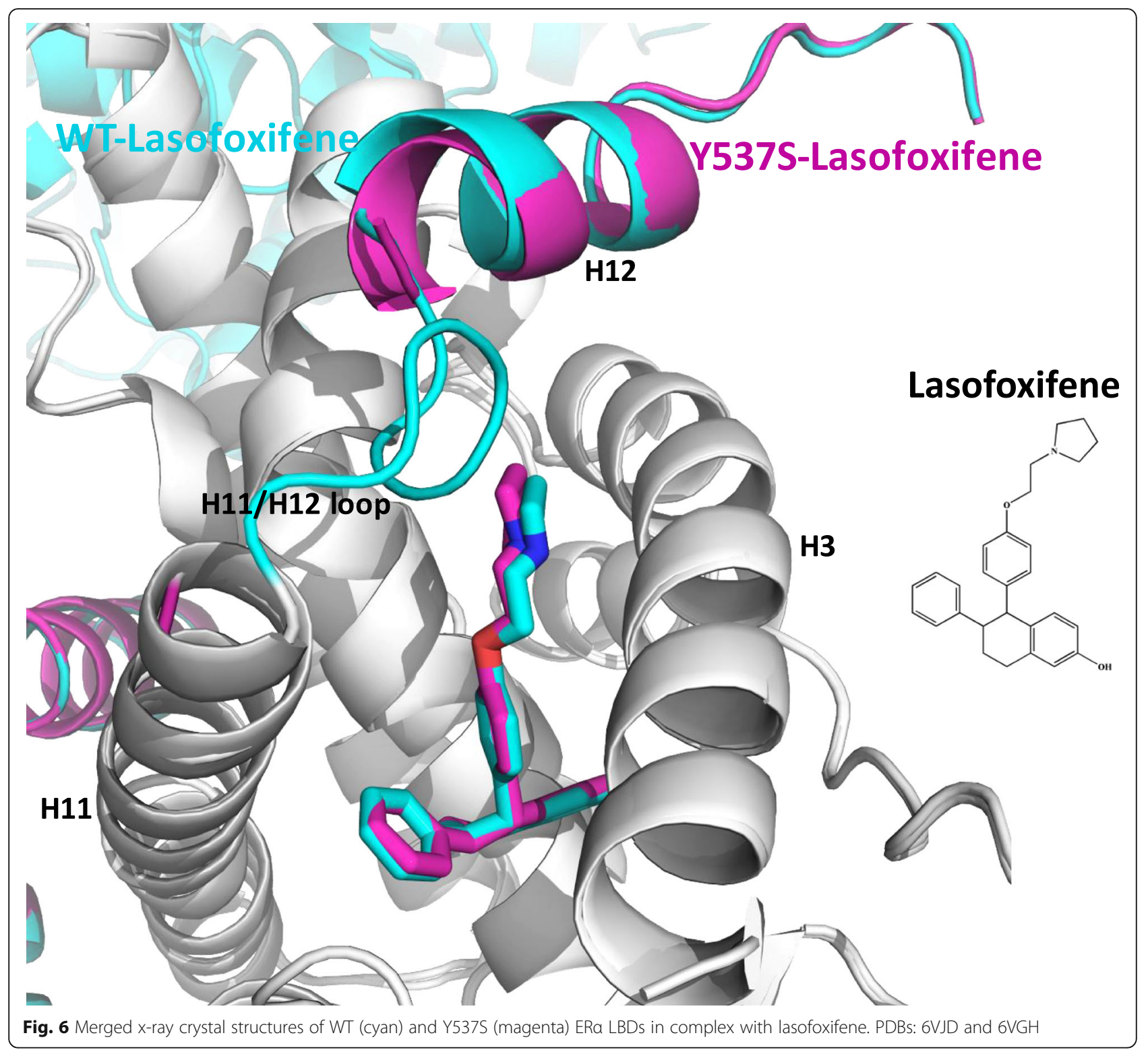

cancer. Luminescence imaging, although semi-quantitative, provided real-time data on tumor growth in vivo, which correlated well with final endpoint tumor weight measurements. The results demonstrate that LAS, a SERM without any demonstrable SERD activity, has clear advantages over FUL, the only clinically approved SERD, at inhibiting primary tumor growth and metastasis in ER+ breast cancer mouse xenografts expressing Y537S and D538G ER $\alpha$ mutants. Notably, LAS as a single agent was superior to both FUL and PAL alone in terms of tumor suppression and metastasis inhibition at the liver, lung, brain, and bone. While improvements were observed for both LAS/PAL and FUL/PAL versus single agent alone, LAS/PAL was significantly more effective than FUL/PAL, demonstrating the potential of LAS in controlling endocrine-resistant ER+ breast cancer.
A MIND model with tumor cells injected directly into the milk ducts was used to establish mouse xenografts. This model was originally developed to follow the natural progression of ductal carcinoma in situ (DCIS) and later used to study invasive breast cancer [28, 29]. Unlike traditional mammary fat pad xenografts which acquire basal characteristics, the MIND model preserves the luminal phenotype of the cells, thus closely mimicking the original ER+ tumor [29]. In addition, the Y537S and D538G ESR1 mutations are heterozygous in the engineered mutant cell lines, more accurately reflecting the natural history of these mutations in refractory breast cancers [10] and adding to the clinical relevance of these in vivo models. 
The improved responses of the ER $\alpha$ mutant tumor explants to LAS alone versus FUL alone are consistent with a published study in cell culture models, which showed that LAS retained its potency in Y537S and D538G ER $\alpha$ mutant cells relative to WT ER $\alpha$ cells, whereas potency for FUL was reduced in the mutant cells [23]. Additionally, the open-label, phase 2a, plasmaMATCH trial showed that FUL alone was ineffective in patients with advanced breast cancer and ESR1 mutations [32], in agreement with our finding of low activities of FUL in ESR1-mutated models. The improved bioavailability of LAS relative to other SERMS, combined with its long half-life and extensive volume of distribution [20,33], likely contributes to its high anti-tumor activity towards ER $\alpha$ mutant tumors. In contrast, the poor pharmaceutical properties of FUL and its potentially insufficient exposure in mutant tumors at the current doses could limit the activity of FUL [23, 34, 35].

To better understand the molecular basis of LAS potency against ER $\alpha$ mutants, biochemical studies were undertaken. Ligand binding assays showed that LAS, like 4-OHT and FUL, had reduced affinities to Y537S and D538G mutants, although the change was smaller compared with 4-OHT or FUL. The affinity data suggest that LAS binds to the ER $\alpha$ mutants as well as or slightly better than 4-OHT and FUL, which potentially promotes the antagonist activity of LAS. However, the difference in Y537S affinity for LAS versus FUL was not substantial enough to explain observed significant difference in antitumor activity between the two, considering the saturating dose of FUL used in our studies.

We also report $\mathrm{x}$-ray crystal structures of WT and Y537S ER $\alpha$ LBDs bound to LAS, demonstrating that both form stable AF2 antagonist conformations. A comparison of the Y537S ER $\alpha$ LBD/LAS structure with that of WT ER $\alpha$ LBD/LAS complex revealed a disrupted H11/H12 loop by the side chain of LAS relative to WT LBD. This loop plays a key role in facilitating the constitutive activities of ER $\alpha$ with mutations in or near the Nterminus of H12 [36] and drugs that increase the dynamic character of $\mathrm{H} 12$ might improve the response of the mutants [13]. Moreover, the loop also contributes to ER stability and disruption of the loop can potentially lead to receptor degradation [13]. LAS has not been shown to affect WT ER degradation; however, its effect on Y537S and D538G mutant ER $\alpha$ needs further investigation. Additionally, $x$-ray crystal structures of SERMs and SERDs in complex with Y537S ER $\alpha$ LBD are also needed to uncover whether specific ligand-induced H12 conformations correlate with improved potencies in breast cancers harboring ESR1 mutants. Overall, the loop disruption observed in Y537S LBD/LAS versus WT LBD/LAS could contribute to the improved efficacy of LAS.
Prevention of metastasis is essential for optimal treatment response and survival in women with therapyresistant breast cancer. The Y537S ER $\alpha$ mutation is generally considered the most resistant to endocrine therapy among the known ER $\alpha$ LBD mutations [15]. In the current studies, Y537S tumors were found to be less sensitive to FUL treatment and more metastatic than D538G tumors. FUL was ineffective in reducing liver and lung metastases in the Y537S model, consistent with previous findings that FUL did not show improvement versus AIs in treating patients with visceral metastases [37]. LAS, on the other hand, significantly inhibited metastasis in vivo to the distal sites of lung, liver, bone, and brain, with almost complete blockades at 5 and $10 \mathrm{mg} /$ $\mathrm{kg}$, demonstrating clear advantages over FUL for controlling metastasis.

Improved survival with FUL/PAL versus FUL/placebo in metastatic ER+ breast cancer after endocrine failure was noted in the PALOMA-3 trial [24, 25]. A network meta-analysis showed that the combinations of CDK4/6 inhibitors, such as PAL, ribociclib, and abemaciclib, with high-dose FUL were among the most effective treatment options for advanced ER+ breast cancer as reflected in overall and progression-free survival [38]. In our studies, while the activity of FUL was significantly improved by PAL as expected, LAS/PAL was more effective than FUL/PAL in general, both at tumor suppression and metastasis inhibition in the Y537S model. Interestingly, LAS alone appeared to be as effective as the combination of LAS plus PAL in some cases. However, efficacies of these treatments need to be verified in patients. The antitumor activity of LAS versus FUL is currently being investigated in the phase 2 ELAINE study (NCT03781063) among women with locally advanced or metastatic ER+/HER2- breast cancer expressing ER $\alpha$ mutants. The follow-up ELAINEII study (NCT04432454) has recently started enrolling patients to further evaluate LAS plus abemaciclib. These studies will provide valuable clinical data on the efficacy and safety of LAS either as a monotherapy or in combination with a CDK4/6 inhibitor for treatment of ESR1-mutated advanced or metastatic breast cancer.

\section{Conclusions}

In conclusion, when compared to FUL, LAS elicited greater anti-tumor activities in preclinical models of breast cancer expressing Y537S and D538G ER $\alpha$. Its best-in-class pharmaceutical characteristics, likely contribute to observed differences between LAS and FUL. Importantly, LAS combined with PAL was in general more effective than the combinations of FUL with PAL in tumor and metastasis inhibition. These results have important clinical implications and demonstrate the potential of using LAS as an effective therapy for women 
with advanced or metastatic ER+ breast cancers expressing constitutively active ESR1 mutations. The ongoing, phase 2 ELAINE studies in women with advanced or metastatic ER+/HER2- breast cancer expressing ER $\alpha$ mutants are expected to provide further clinical data regarding the efficacy and safety of LAS as an antitumor therapy.

\section{Abbreviations}

4-OHT: 4-Hydroxytamoxifen; AF2: Activating function-2; Al: Aromatase inhibitor; DCIS: Ductal carcinoma in situ; E2: Estradiol; ER: Estrogen receptor; FUL: Fulvestrant; GFP: Green fluorescent protein; H\&E: Hematoxylin and eosin; IHC: Immunohistochemical; LAS: Lasofoxifene; LBD: Ligand binding domain; MBC: Metastatic breast cancer; MIND: Mammary intraductal; PDB: The Protein Data Bank; s.c.: Subcutaneous; SERD: Selective estrogen receptor down regulator; SERM: Selective estrogen receptor modulator; PAL: Palbociclib; PEARL: The Postmenopausal Evaluation and Risk-Reduction with Lasofoxifene trial; WT: Wild type

\section{Supplementary Information}

The online version contains supplementary material available at https://doi. org/10.1186/s13058-021-01431-w.

Additional file 1: Supplemental Table S1. X-ray crystallographic statistics. Description of data: The table summarizes $X$-ray crystallographic data collection and refinement statistics for ERa LBD WT/Lasofoxifene and ERa LBD Y537S/Lasofoxifene complexes.

Additional file 2: Supplementary Table S2. Summary of bone metastasis results ( $n=5-6$ mice). Description of data: The table summarizes the results on bone metastasis in different treatment groups.

Additional file 3: Supplementary Figure S1. $2 \mathrm{mFo}-D F c$ difference maps showing the maps for lasofoxifene in the (A) wild type and (B) Y537S ligand binding pocket of ERa ligand binding domain contoured to $1.5 \sigma$. Description of data: The figure shows $2 \mathrm{mFo}-\mathrm{DFc}$ difference maps for representative lasofoxifene ligands in the ERa LBD binding pocket for the wild-type and Y537S structures.

Additional file 4: Supplementary Figure S2. In vivo luminescence images of mice bearing tumors expressing MCF7 WT, Y537S, and D538G ERa at day 56 after treatment initiation. FUL, fulvestrant; LAS, lasofoxifene; Veh, vehicle. Description of data: The figure provides in vivo luminescence images of tumor-bearing mice after treatment with vehicle, fulvestrant, and lasofoxifene (3 mice per treatment group).

Additional file 5: Supplementary Figure S3. Histological analysis of excised long bones in the Y537S ERa mutant model. (A) An example of H\&E staining of bone marrow for a vehicle-treated mouse. Insert shows bone metastases stained with anti-luciferase antibody (left) and H\&E staining (right). (B) An example of H\&E staining of bone marrow for a $5 \mathrm{mg} / \mathrm{kg}$ lasofoxifene-treated mouse. No metastases were observed. Description of data: The figure shows examples of H\&E and IHC staining images of bone marrow after treatment with vehicle and lasofoxifene.

\section{Acknowledgements}

The authors appreciate the medical writing and editorial assistance of Hui Zhang, PhD, and Kathleen Ohleth, PhD. Structural results shown in this report are derived from work performed at Argonne National Laboratory (ANL), Structural Biology Center (SBC) at the Advanced Photon Source (APS), under US Department of Energy, Office of Biological and Environmental Research contract DE-AC02-06CH1 1357.

\section{Authors' contributions}

$M L, B K$, and GLG conceived of the study. ML, SWF, and MEG developed methodology for the study. ML, SWF, YFC, BG, MEG, JDK, LP, and GLG participated in the data acquisition. ML, SWF, MEG, and GLG participated in the data analysis and interpretation. ML, SWF, BK, JDK, and GLG wrote and/or edited the manuscript. All authors read and approved the final manuscript.

\section{Funding}

Sermonix provided a research grant to the University of Chicago for conducting the reported research. Structural studies were supported by US Department of Energy, Office of Biological and Environmental Research contract DE-AC02-06CH11357. Sermonix also supported the medical writing assistance of Hui Zhang, PhD, and Kathleen Ohleth, PhD (Precise Publications, LLC).

Availability of data and materials

All data generated or analyzed during the current study are available from the corresponding author on reasonable request.

\section{Declarations}

Ethics approval and consent to participate

The Institutional Animal Care and Use Committee at the University of Chicago approved all animal procedures.

Consent for publication

Not applicable.

\section{Competing interests}

GLG has received research funding from, has consulted for, and owns stock or stock options from Sermonix Pharmaceuticals and Olema Pharmaceuticals. SWF has received research funding from Olema Pharmaceuticals. BK has consulted for Sermonix Pharmaceuticals. No potential conflicts of interest were disclosed by the other authors.

\section{Author details}

${ }^{1}$ The Ben May Department for Cancer Research, The University of Chicago, 929 East 57th Street, GCIS W421C, Chicago, IL 60637, USA. 'Department of Cancer Biology, Loyola University Chicago, Maywood, IL, USA. ${ }^{3}$ Komm-Sandin Pharma Consulting, Newtown Square, PA, USA.

Received: 2 February 2021 Accepted: 20 April 2021

Published online: 12 May 2021

References

1. Bray F, Ferlay J, Soerjomataram I, Siegel RL, Torre LA, Jemal A. Global cancer statistics 2018: GLOBOCAN estimates of incidence and mortality worldwide for 36 cancers in 185 countries. CA Cancer J Clin. 2018;68(6):394-424. https://doi.org/10.3322/caac.21492.

2. Hwang KT, Kim J, Jung J, Chang JH, Chai YJ, Oh SW, et al. Impact of breast cancer subtypes on prognosis of women with operable invasive breast cancer: a population-based study using SEER Database. Clin Cancer Res. 2019:25(6):1970-9. https://doi.org/10.1158/1078-0432.CCR-18-2782.

3. Jeselsohn R, De Angelis C, Brown M, Schiff R. The evolving role of the estrogen receptor mutations in endocrine therapy-resistant breast cancer. Curr Oncol Rep. 2017;19(5):35. https://doi.org/10.1007/s11912-017-0591-8.

4. Osborne CK, Schiff R. Mechanisms of endocrine resistance in breast cancer. Annu Rev Med. 2011;62(1):233-47. https://doi.org/10.1146/annurev-med070909-182917.

5. Jordan VC, O'Malley BW. Selective estrogen-receptor modulators and antihormonal resistance in breast cancer. J Clin Oncol. 2007;25(36):5815-24. https://doi.org/10.1200/JCO.2007.11.3886.

6. Fan $\mathrm{P}$, Jordan VC. New insights into acquired endocrine resistance of breast cancer. Cancer Drug Resist. 2019;2:198-209. https://doi.org/10.20517/cdr.201 9.13.

7. Pan H, Gray R, Braybrooke J, Davies C, Taylor C, McGale P, et al. 20-Year risks of breast-cancer recurrence after stopping endocrine therapy at 5 years. $\mathrm{N}$ Engl J Med. 2017;377(19):1836-46. https://doi.org/10.1056/NEJMoa1701830.

8. Boer K. Fulvestrant in advanced breast cancer: evidence to date and place in therapy. Ther Adv Med Oncol. 2017;9(7):465-79. https://doi.org/10.1177/1 758834017711097

9. Tsuboi K, Kaneko Y, Nagatomo T, Fujii R, Hanamura T, Gohno T, et al. Different epigenetic mechanisms of ERalpha implicated in the fate of fulvestrant-resistant breast cancer. J Steroid Biochem Mol Biol. 2017;167: 115-25. https://doi.org/10.1016/j.jsbmb.2016.11.017.

10. Jeselsohn R, Yelensky R, Buchwalter G, Frampton G, Meric-Bernstam F, Gonzalez-Angulo AM, et al. Emergence of constitutively active estrogen receptor-alpha mutations in pretreated advanced estrogen receptor-positive 
breast cancer. Clin Cancer Res. 2014;20(7):1757-67. https://doi.org/10.1158/1 078-0432.CCR-13-2332.

11. Toy W, Shen Y, Won H, Green B, Sakr RA, Will M, et al. ESR1 ligand-binding domain mutations in hormone-resistant breast cancer. Nat Genet. 2013; 45(12):1439-45. https://doi.org/10.1038/ng.2822.

12. Merenbakh-Lamin K, Ben-Baruch N, Yeheskel A, Dvir A, Soussan-Gutman L, Jeselsohn R, et al. D538G mutation in estrogen receptor-alpha: a novel mechanism for acquired endocrine resistance in breast cancer. Cancer Res. 2013;73(23):6856-64. https://doi.org/10.1158/0008-5472.CAN-13-1197.

13. Fanning SW, Mayne CG, Dharmarajan V, Carlson KE, Martin TA, Novick SJ, et al. Estrogen receptor alpha somatic mutations Y537S and D538G confer breast cancer endocrine resistance by stabilizing the activating function-2 binding conformation. eLife. 2016;5. https://doi.org/10.7554/eLife.12792.

14. Zhao Y, Laws MJ, Guillen VS, Ziegler Y, Min J, Sharma A, et al. Structurally novel antiestrogens elicit differential responses from constitutively active mutant estrogen receptors in breast cancer cells and tumors. Cancer Res. 2017;77(20):5602-13. https://doi.org/10.1158/0008-5472.CAN-17-1265.

15. Jeselsohn R, Bergholz JS, Pun M, Cornwell M, Liu W, Nardone A, et al. Allelespecific chromatin recruitment and therapeutic vulnerabilities of ESR1 activating mutations. Cancer Cell. 2018;33(2):173-186.e175. https://doi.org/1 0.1016/..ccell.2018.01.004

16. Pinkerton JV, Conner EA. Beyond estrogen: advances in tissue selective estrogen complexes and selective estrogen receptor modulators. Climacteric. 2019;22(2):140-7. https://doi.org/10.1080/13697137.2019.15684 03.

17. Wardell SE, Nelson ER, Chao CA, McDonnell DP. Bazedoxifene exhibits antiestrogenic activity in animal models of tamoxifen-resistant breast cancer: implications for treatment of advanced disease. ClinCancer Res. 2013;19(9):2420-31. https://doi.org/10.1158/1078-0432.CCR-12-3771.

18. Wardell SE, Ellis MJ, Alley HM, Eisele K, VanArsdale T, Dann SG, et al. Efficacy of SERD/SERM hybrid-CDK4/6 inhibitor combinations in models of endocrine therapy-resistant breast cancer. Clin Cancer Res. 2015;21(22): 5121-30. https://doi.org/10.1158/1078-0432.CCR-15-0360.

19. Komm BS, Chines AA. An update on selective estrogen receptor modulators for the prevention and treatment of osteoporosis. Maturitas. 2012;71(3):2216. https://doi.org/10.1016/j.maturitas.2011.11.018.

20. Fablyn (lasofoxifene tartrate) Summary of Product Characteristics. In: Pfizer Inc:; 2009.

21. LaCroix AZ, Powles T, Osborne CK, Wolter K, Thompson JR, Thompson DD, et al. Breast cancer incidence in the randomized PEARL trial of lasofoxifene in postmenopausal osteoporotic women. JNatlCancer Inst. 2010;102(22): 1706-15. https://doi.org/10.1093/jnci/djg415.

22. Mocellin S, Pilati P, Briarava M, Nitti D. Breast cancer chemoprevention: a network meta-analysis of randomized controlled trials. J Natl Cancer Inst. 2016;108(2). https://doi.org/10.1093/jnci/djv318.

23. Andreano KJ, Baker JG, Park S, Safi R, Artham S, Oesterreich S, et al. The dysregulated pharmacology of clinically relevant ESR1 mutants is normalized by ligand-activated WT receptor. Mol Cancer Ther. 2020;19(7): 1395-405. https://doi.org/10.1158/1535-7163.MCT-19-1148.

24. Loibl S, Turner NC, Ro J, Cristofanilli M, Iwata H, Im SA, et al. Palbociclib combined with fulvestrant in premenopausal women with advanced breast cancer and prior progression on endocrine therapy: PALOMA-3 results. Oncologist. 2017;22(9):1028-38. https://doi.org/10.1634/theoncologist.20170072 .

25. Turner NC, Slamon DJ, Ro J, Bondarenko I, Im SA, Masuda N, et al. Overall survival with palbociclib and fulvestrant in advanced breast cancer. N Engl J Med. 2018;379(20):1926-36. https://doi.org/10.1056/NEJMoa1810527.

26. Bahreini A, Li Z, Wang P, Levine KM, Tasdemir N, Cao L, et al. Mutation site and context dependent effects of ESR1 mutation in genome-edited breast cancer cell models. Breast Cancer Res. 2017;19(1):60. https://doi.org/10.1186/ s13058-017-0851-4.

27. Liu H, Patel MR, Prescher JA, Patsialou A, Qian D, Lin J, et al. Cancer stem cells from human breast tumors are involved in spontaneous metastases in orthotopic mouse models. Proc Natl Acad Sci U S A. 2010;107(42):18115-20. https://doi.org/10.1073/pnas.1006732107.

28. Behbod F, Kittrell FS, LaMarca H, Edwards D, Kerbawy S, Heestand JC, et al. An intraductal human-in-mouse transplantation model mimics the subtypes of ductal carcinoma in situ. Breast Cancer Res. 2009;11(5):R66. https://doi. org/10.1186/bcr2358

29. Sflomos G, Dormoy V, Metsalu T, Jeitziner R, Battista L, Scabia V, et al. A preclinical model for ERalpha-positive breast cancer points to the epithelial microenvironment as determinant of luminal phenotype and hormone response. Cancer Cell. 2016;29(3):407-22. https://doi.org/10.1016/j.ccell.2016. 02.002.

30. Fanning SW, Hodges-Gallagher L, Myles DC, Sun R, Fowler CE, Plant IN, et al. Specific stereochemistry of OP-1074 disrupts estrogen receptor alpha helix 12 and confers pure antiestrogenic activity. Nat Commun. 2018;9(1):2368. https://doi.org/10.1038/s41467-018-04413-3.

31. Fanning SW, Jeselsohn R, Dharmarajan V, Mayne CG, Karimi M, Buchwalter $\mathrm{G}$, et al. The SERM/SERD bazedoxifene disrupts ESR1 helix 12 to overcome acquired hormone resistance in breast cancer cells. elife. 2018;7. https://doi. org/10.7554/eLife.37161

32. Turner NC, Kingston B, Kilburn LS, Kernaghan S, Wardley AM, Macpherson IR et al. Circulating tumour DNA analysis to direct therapy in advanced breast cancer (plasmaMATCH): a multicentre, multicohort, phase 2a, platform trial. Lancet Oncol. 2020;21(10):1296-308. https://doi.org/10.1016/S1470-2045(2 0)30444-7.

33. Gennari L. Lasofoxifene, a new selective estrogen receptor modulator for the treatment of osteoporosis and vaginal atrophy. Expert Opin Pharmacother. 2009;10(13):2209-20. https://doi.org/10.1517/1465656090312 7241.

34. van Kruchten $M$, de Vries EG, Glaudemans AW, van Lanschot MC, van Faassen M, Kema IP, et al. Measuring residual estrogen receptor availability during fulvestrant therapy in patients with metastatic breast cancer. Cancer Discov. 2015;5(1):72-81. https://doi.org/10.1158/2159-8290.CD-14-0697.

35. Wardell SE, Yllanes AP, Chao CA, Bae Y, Andreano KJ, Desautels TK, et al. Pharmacokinetic and pharmacodynamic analysis of fulvestrant in preclinical models of breast cancer to assess the importance of its estrogen receptor-a degrader activity in antitumor efficacy. Breast Cancer Res Treat. 2020;179(1): 67-77. https://doi.org/10.1007/s10549-019-05454-y.

36. Katzenellenbogen JA, Mayne CG, Katzenellenbogen BS, Greene GL, Chandarlapaty S. Structural underpinnings of oestrogen receptor mutations in endocrine therapy resistance. Nat Rev Cancer. 2018;18(6):377-88. https:// doi.org/10.1038/s41568-018-0001-z.

37. Robertson JFR, Bondarenko IM, Trishkina E, Dvorkin M, Panasci L, Manikhas A, et al. Fulvestrant $500 \mathrm{mg}$ versus anastrozole $1 \mathrm{mg}$ for hormone receptorpositive advanced breast cancer (FALCON): an international, randomised, double-blind, phase 3 trial. Lancet. 2016;388(10063):2997-3005. https://doi. org/10.1016/S0140-6736(16)32389-3.

38. Brandao M, Maurer C, Ziegelmann PK, Ponde NF, Ferreira A, Martel S, et al. Endocrine therapy-based treatments in hormone receptor-positive/HER2negative advanced breast cancer: systematic review and network metaanalysis. ESMO Open. 2020;5(4). https://doi.org/10.1136/esmoopen-2020000842.

\section{Publisher's Note}

Springer Nature remains neutral with regard to jurisdictional claims in published maps and institutional affiliations.

\section{Ready to submit your research? Choose BMC and benefit from:}

- fast, convenient online submission

- thorough peer review by experienced researchers in your field

- rapid publication on acceptance

- support for research data, including large and complex data types

- gold Open Access which fosters wider collaboration and increased citations

- maximum visibility for your research: over $100 \mathrm{M}$ website views per year

At BMC, research is always in progress.

Learn more biomedcentral.com/submission 